\title{
SOUND SYMBOLISM IN FOREIGN LANGUAGE PHONOLOGICAL ACQUISITION
}

\author{
MAGDALENA WREMBEL \\ magdala@amu.edu.pl \\ Adam Mickiewicz University
}

\begin{abstract}
The paper aims at investigating the idea of a symbolic nature of sounds and its implications for in the acquisition of foreign language phonology. Firstly, it will present an overview of universal trends in phonetic symbolism, i.e. non-arbitrary representations of a phoneme by specific semantic criteria. Secondly, the results of a preliminary study on different manifestations of sound symbolism including emotionally-loaded representations of phonemes and other synaesthetic associations shall be discussed. Finally, practical pedagogical implications of sound symbolism will be explored and a number of innovative classroom activities involving sound symbolic associations will be presented.
\end{abstract}

Key words: sound symbolism, synaesthetic vowel mappings, pronunciation pedagogy

\section{Introduction}

The aims of the paper are threefold; it is intended to investigate the idea of a symbolic nature of sounds, to explore acoustic iconicity in the context of the acquisition of foreign language phonology, and finally to search for potential implications for L2 pronunciation pedagogy.

The paper starts with an overview of research into sound symbolism as well as the presentation of its typology, iconic strategies and motivation behind the phenomenon. Then the results of a study into synaesthetic associations, i.e. visualising English vowel sounds in terms of different sensory and emotionally-loaded representations shall be presented and discussed. The paper ends with an overview of innovative classroom activities based on sound symbolic associations aimed at enhancing foreign language phonological acquisition.

\section{Sound symbolism - an overview}

Although it is generally acknowledged in the linguistic theory that the relation between sound and meaning is arbitrary as "no one disputes the principle of the arbitrary nature of the [linguistic] sign" (de Saussure 1966: 68), there have been several attempts throughout history that questioned this assumption demonstrating that the assignment of 
the signifier to signified is not always totally arbitrary. The debate between 'conventionalism' and 'naturalism' can be traced back to Plato's Cratylus, one of the earliest philosophical texts of the Classical Greek period to deal with matters of etymology and linguistics, in which the protagonist argues that the relationship of sign to signified is object to imitation since "[names] are natural and not conventional (...), there is a truth or correctness in them" (Plato as quoted in Hinton et al 2006: 1). Plato goes on to explain that some important words are encoded descriptions of objects, but not perfect encapsulations of their objects' essences. The majority of Chinese ancient philosophers, including the Confucianists, came to the opposite conclusion proclaiming a totally arbitrary relationship resulting from convention and popular usage (e.g. Xun Zi 221 BC, as quoted in Lapolla 2006: 130), however, there were also attempts to find the true sound-meaning correspondence.

The contemporary literary theory assumes the conventionalist stance in which the relation of the sound and meaning is completely arbitrary in accordance with de Saussure's (1966) principle of the arbitrary nature of the linguistic sign. Sound symbolism, on the other hand, has a tarnished reputation in current linguistics for several reasons including ill-structured iconic patterns, incorrect use of 'universal' and conflicting results of empirical studies (cf. Diffloth 2006). However, due to a considerable accumulation of cross-linguistic data on sound symbolism in the past decades and an increased interest in this phenomenon some scholars put forward a claim that sound symbolism plays a more significant role in the theory of language that has been recognised so far (cf. Hinton et al. 2006: 1).

The beginning of scientific interest in natural associations of sounds and meaning was marked by Sapir's $(1927,1929)$ often quoted studies into sound symbolism, in which he examined examples of acoustic iconicity, particularly for the 'large' vs. 'small' categorical distinction. It was followed by Jespersen (1933), who on the basis of the analyses of the languages he was familiar with, put forward a hypothesis concerning the correlation between certain types of sounds and certain categories of meaning such as size, movement or distance.

The design of several experiments conducted in the first half of the $20^{\text {th }}$ century involved word-matching studies which required the participants to match antonymic pairs of words from one language with connotatively or denotatively equivalent lexical items in an unknown language. The findings of the majority of these experiments pointed unambiguously to regular tendencies in associating particular sensations (e.g. size, shape, colour, texture, movement) with specific acoustic quality of phonemic segments (cf. Berlin 2006: 76). For instance, Jespersen (1933) pointed to a common association of 'quickness' with front vowels, particularly [i] in many natural languages, e.g. French, Italian, Danish, Swedish. Swadesh (1971), on the other hand, noted sound symbolic associations of voiceless obstruents with sharp and rapid movements; and of nasals with heavy and slow continuity.

The most recent and comprehensive investigation into the symbolic nature of sounds is that by Hinton et al. (2006), who published an edited collection presenting recent cross-disciplinary findings in the field depicted from different perspectives, e.g. linguistic, anthropological, biological and literary. Numerous contributions to the volume illustrate sound symbolic tendencies in natural languages of the world encompassing native American languages as well as languages of Latin America, Asia, 
Australia, Africa and Europe, with a particular emphasis on English. For instance, Berlin (2006) reported a pattern of sound-symbolic marking in ethnoornithological lexicon in Huambisa, in which bird names feature a considerable number of segments of high acoustic frequency evoking connotations of quick and rapid motion, whereas fish names involve predominantly low-frequency segments associated with slow continuous flow (2006: 91). Lapolla (2006), on the other hand, in an experimental investigation into Mandarin Chinese demonstrated that Chinese exhibits some sound-symbolic patterns that are perceptible to English monolingual speakers. To quote yet another study from the edited collection, Rhodes (2006) conducted a submorphemic analysis of English simplex words to identify symbolic mappings of forms labelling aural images (i.e. images from all modes of perception: visual, aural, tactile, taste, etc). The prevalent research question that emerges from these multitude of studies is to which extent the language form is linked to meaning. The editors, Hinton, Nichols and Ohala, conclude that the two can never be totally separated and that "linguistic theory must accommodate itself to that increasingly obvious fact" (2006: 12).

\section{Typology of sound symbolism}

The concept of sound symbolism is understood as the existence of a direct link between sound and meaning. The degree of this linkage can be subject to a considerable variation, therefore, a typology proposed by Hinton et al. (2006: 2-7) involves: (1) corporeal; (2) imitative; (3) synaesthetic; (4) conventional; and (5) metalinguistic sound symbolism.

Corporeal sound symbolism is used to express internal states of the speaker (emotional or physical) by means of certain sounds or intonation patterns. This category involves involuntary symptomatic sounds (such as coughing, hiccups), vocatives (e.g. bilabial clicks, whistles) and expressive intonation or voice quality. It can be argued that it is not true sound symbolism as the sound functions as a symptom or sign rather than a symbol.

The imitative category includes onomatopeic words representing sounds of the environment e.g. bang, bow-wow, knock and refers to sound patterns outside of conventional speech; sounds made by animals (e.g. meow, moo, tweat); rhythmic movements translated into sounds (e.g. ding dong). It represents a direct mapping between the acoustic features of the sound and phonological features of the word which labels it.

In synaesthetic sound symbolism certain vowels, consonants and suprasegmentals are selected to represent visual and tactile properties of objects, e.g. size, shape. For instance, high vowels and palatal consonants are frequently used for diminutive marking or words that represent small objects. On the other hand, deep voice and vowel lengthening are applied when talking about large objects. This type of size symbolism was found to exhibit fairly universal tendencies as evidenced by Sapir (1929) or Ultan (1978) and it is the most frequent subject of study.

Conventional sound symbolism is a process in which certain phonemes and clusters are associated with certain meanings, e.g. 'gl': glitter, glimmer, glow, glisten, 'kl': clank, click, clip (cf. Rhodes 2006: 277). It is largely language-specific rather than universal, and is often used in creating words for commercial products. 
In metalinguistic symbolism, the choice of symbols and intonation patterns signals aspects of linguistic structure and function. It serves to express grammar phenomena: tense, aspect, pluralization, e.g. goose/geese; parts of speech - signalled by vowel quality, stress placement, e.g. 'record, re'cord; or a preference for particular phonemes in certain parts of speech or affixes.

\section{Sound symbolic strategies and motivation}

In spite of a largely language-specific character of the conducted studies on sound symbolism, there emerge certain universal iconic strategies, such as reduplication, marked use of unusual segments or the association of certain phoneme classes with specific semantic fields (cf. Hinton et al. 2006: 9).

Reduplication is a very common sound symbolic strategy in languages around the world, however, it is not very productive in English or other European languages. English examples include mostly partial reduplication with vowel alternation, e.g. dingdong, wishy-washy, dilly-dally. The symbolic patterns that are widely discussed in the literature involve the associations of particular phonemes with specific meanings, e.g. stops are used to imitate abrupt sounds or actions (pop, tap, tick, bop), nasals often imitate ringing (ding-dong), fricatives - quick audible motion and air turbulence (whizz, puff, shush, hush, continuants - lasting acts and strong swift movement (swoosh, whoosh) (cf. Oswalt 2006).

On the basis of the universal size-sound symbolism attested in numerous studies (e.g. Sapir 1927, Jespersen 1933), Ohala (1984) proposed the so called Frequency Code hypothesis.

\footnotetext{
"Words denoting or connoting SMALL or SMALLNESS ... tend to exhibit a disproportionate incidence of vowels and/or consonants characterised by high acoustic frequency. Words denoting or connoting LARGE use segments with low acoustic frequency. In consonants, voiceless obstruents have higher frequency than voiced because of their higher velocity of the airflow, ejectives higher than plain stops ... dental, alveolar, palatal and front velars higher than labials and back velars. In the case of vowels, high front vowels have higher F2 and low back vowels the lowest F2" (Ohala 1984: 9).
}

In this universal 'frequency-code' high-frequency sounds, i.e. /i:/ and /I/ are typically associated with small size and sharpness, rapid movement, and physically high objects, whereas low frequency sounds, i.e. $/ \mathrm{u} /$ and $/ \mathrm{a} /$ tend to symbolise large size, softness, slow movement, and physically low objects (Ohala 2006).

Trying to account for the rationale behind sound symbolic use, scholars point to the fact that it serves greater ease of communication and they hypothesise that it is possibly a precursor of fully formed human languages. Reaction-time experiments show that correct judgement of meaning is faster for sound-symbolic words than for arbitrary ones (Sereno 2006).

Ohala (1984) points to the biological bases of sound symbolism by analysing closecontact competitive encounters between vocalising animals, in which the aggressor uses low-frequency staccato to appear as large as possible (e.g. dog's growl) and the opponent uses high-frequency vocalisations to appear smaller, non-threatening (e.g. 
whine, yelp). He draws parallel conclusions for speech sounds, where high $\mathrm{F}_{0}$ is used to signal defence, politeness, and submission, whereas low $\mathrm{F}_{0}$ symbolises authority, aggression, and confidence.

Another source of motivation for iconicity is physiologically motivated, i.e. articulatory feedback is associated with proprioceptive sensation. For instance, the sizesymbolic dichotomy between /i/ vs. /a/ as representing 'big' vs. 'small' can be explained by the differences in the volume of the tongue or the size of the air passage, however, it still remains culturally relative (cf. Hinton et al 2006).

\section{Experiment}

The present paper aims to contribute to the recently re-evoked interest in acoustic iconicity by exploring different manifestations of phonetic symbolism. First of all, a preliminary study on synaesthetic associations i.e. visualising a sound in terms of different modes of perception, aesthetic values or emotionally-loaded representations shall be presented. Then the findings will be interpreted against some recent sound symbolic studies (e.g. Hinton et al. 2006) and, in particular, they will be discussed in the light of previous experiments on sound-colour coding conducted by the present author (Wrembel 2007, Wrembel \& Rataj 2008, Wrembel 2009).

\subsection{Participants and procedure}

The participants of the study included 59 first- and second-year students of the School of English at Adam Mickiewicz University, Poznań, Poland. Their mean age was 19.5 and their proficiency level of English was between intermediate and upper-intermediate. They were all subject to phonetic training in the course of their studies.

The aim of the study was to investigate whether there are any significant trends in the sound symbolic associations between the English vowel sounds and a provided set of adjectives. The study was conducted on EFL learners of English as it was expected to generate some potential implications for foreign language pronunciation pedagogy, however, future research is intended to involve also English native speakers as informants to verify the present findings.

The participants were asked to make associations with 12 English vowels while completing a specially designed questionnaire (see Appendix 1). Their task was to match their mental representations of a particular phoneme to 8 polar adjective pairs presented in the form of a 7-point Likert scale. The matching task involved a selection of one of antonymic words in each category which appeared more connotatively equivalent to a particular sound and to indicate the matching strength by means of the provided scale. The adjectives represented salient visual or tactile characteristics of objects, i.e. size, colour, texture, shape as well as their emotional loading. The questionnaire included the following pairs of adjectives: big vs. small; bright vs. dark; soft vs. hard; pleasant vs. unpleasant; high vs. low; happy vs. sad; female vs. male; quiet vs. aggressive. 


\subsection{Results}

A statistical analysis was performed in order to examine whether the synaesthetic mappings between the English vowel sounds and the eight polar adjective pairs were random or not. The results were analysed using a One-Sample $t$-Test in order to verify whether the mean of a variable differed significantly from a test value 4 , which indicated a median value not pointing to any of the polar adjectives.

Each polar adjective pair was analysed separately for the whole set of individual vowels (an exemplary statistical analysis for the 'bright' vs. 'dark' category is presented in Table 1) and then a joint analysis of vowel categories was performed (long vs. short; front/central/back; high/mid/low). The analysis was both qualitative and quantitative.

Table 1 T-test analysis for 'bright' vs. 'dark' English vowel associations

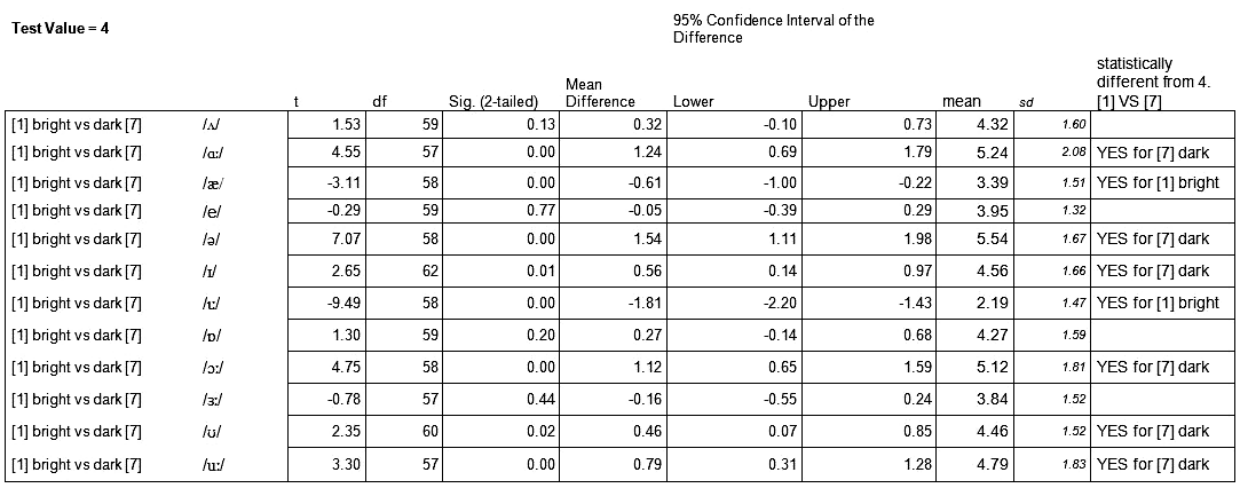

In terms of the size symbolism, the following vowels demonstrated a statistically significant preference for 'big': /i:/ /æ/ /a:/ /o:/ /u:/ /3:/, whereas /I/ /e/ / $/ / \Lambda / / \mathrm{U} / \mathrm{o} /$ were predominantly assigned to the 'small' category. The individual vowel results correspond to the joint categorical analysis. In the joint analysis of long vs. short vowels statistically significant differences were observed for 2 variables relating to size and salience (see Table 2). There was a noticeable tendency to associate the English long vowels with the terms 'big' and 'aggressive', whereas the short vowels triggered predominant associations with 'small' and 'quiet' $(\mathrm{p}<.01)$.

Table 2 T-test results for 'big' vs. 'small' and 'quiet' vs. 'aggressive' - vowel categories analysis

\begin{tabular}{|c|c|c|c|c|c|c|c|c|c|c|}
\hline & & \multicolumn{9}{|c|}{ Test Value $=4$} \\
\hline & & \multirow{2}{*}{$\mathrm{t}$} & \multirow{2}{*}{ df } & \multirow{2}{*}{ Sig. (2-tailed) } & \multirow{2}{*}{ Mean Difference } & \multicolumn{5}{|c|}{$95 \%$ Confidence Interval of the Difference } \\
\hline & & & & & & Lower & Upper & mean & $s d$ & diff from 4 [1] VS [7] \\
\hline [1] big vs small [7] & long vowels & -15.85 & 353 & 0.00 & -1.38 & -1.55 & -1.21 & 2.62 & 1.64 & YES for [1] \\
\hline [1] big vs small [7] & short vowels & 13.65 & 349 & 0.00 & 1.23 & 1.05 & 1.40 & 5.23 & 1.68 & YES for [7] \\
\hline [1] quiet vs aggressive [7] & Iong vowels & 3.67 & 350 & 0.00 & 0.30 & 0.14 & 0.45 & 4.30 & 1.51 & YES for [7] \\
\hline [1] quiet vs aggressive [7] & short vowels & -2.20 & 352 & 0.03 & -0.17 & -0.32 & -0.02 & 3.83 & 1.45 & YES for [1] \\
\hline
\end{tabular}


As far as vowel-to-luminescence mappings are concerned, the individual analysis of vowels pointed to statistically significant associations for / $/$ / /æ/ with 'bright' and for /a:/ /o:/ /ui//3:/ / / / with 'dark'. These results correspond to a large extent to the front vs. back joint vowel analysis, in which the front vowels $/ \mathrm{i} / / \mathrm{I} / / \mathfrak{z} / / \mathrm{e} /$ tend to be categorised as 'bright', whereas back and central as 'dark'.

The vowel-to-texture correspondence involving the 'soft' vs. 'hard' distinction yielded fewer statistically significant results. The vowels /I/ /æ/ /3:/ were perceived symbolically as 'hard', whereas /i:/ /ui//a/ as soft. No vowel categories produced any significant results.

The individual vowel analysis of categories related to emotional loading involved the 'pleasant' vs. 'unpleasant' and 'happy' vs. 'sad' distinctions. The former resulted in the vowels /i:/ /e/ /a:/ /o:/ / / / /u:/ perceived as 'pleasant' and only the vowel /3:/ assigned to the 'unpleasant' category. The joint vowel analysis confirmed partially the results as high and back vowels were categorised as 'pleasant' and none of the analysed vowel categories yielded any statistical significance in the assignment to the 'unpleasant' category.

The 'happy' vs. 'sad' analysis pointed to the vowels /i:/ /æ/ being associated predominantly with 'happy' and /a:/ / : $/ / \mathrm{u}: / / \Lambda /$ /3:/ with 'sad'. There is a partial correspondence with categorical mappings, with front vowels perceived symbolically as 'happy' and back/central and low/mid as 'sad'.

The analysis of the location-to-vowel mappings (i.e. high vs. low) demonstrated that /i:/ was associated above the chance level with 'high' and /a:/ /o:/ / / / / / /3:/ with 'low'. The analysis of vowel categories pointed to the front vowels characterised as 'high' and back and central as 'low'.

In the gender-to-vowel correlations only the vowel /i:/ demonstrated statistically significant associations with the 'female' category, whereas /I/ /e/ /a:/ /o:/ /3:/ were selected to symbolise 'male'. In the joint vowel analysis low/mid and back/central vowels were statistically more frequently assigned to 'male', however, no vowel categories were found to symbolise 'female'.

In the salience-to-vowel mappings, individual vowels characterised as 'quiet' included $/ \mathrm{u} / \mathrm{\jmath} /$ while $/ \mathfrak{æ} / / 3 \mathrm{z} /$ were assigned to 'aggressive'. The vowel categories analysis indicated that long tense vowels symbolised 'aggressiveness' and short lax vowels - 'quietness'.

In the conducted analysis of synaesthetic mappings for English vowels, the vowel categories corresponded to the vertical and horizontal movements of the tongue. It was found that the front English vowels were associated above chance level with 'bright', 'high', 'happy' and 'aggressive'; the central vowels with 'small', 'dark', 'low', 'male' and 'sad'; whereas the back vowels with 'big, 'dark', 'pleasant', 'low', 'sad', and 'male' (see Fig. 1). On the other hand, for the high vowels the only statistically significant adjective mapping was with 'pleasant'; the mid vowels triggered associations with 'dark', 'low', 'sad', and 'male'; and the low vowels with 'big', 'dark', 'low', 'sad', 'aggressive' and 'male' (see Fig. 2). Some adjectives were matched above chance level with more than one vowel category, e.g. male, sad, low, dark were mapped both with central and back vowels. 


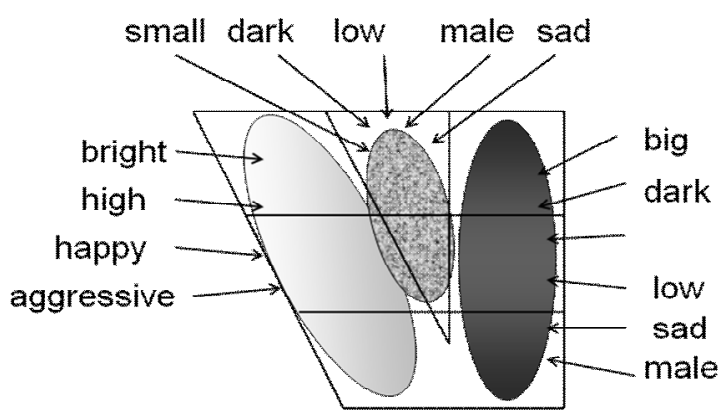

Fig. 1 Statistically significant synaesthetic mappings for front/central/back English vowels

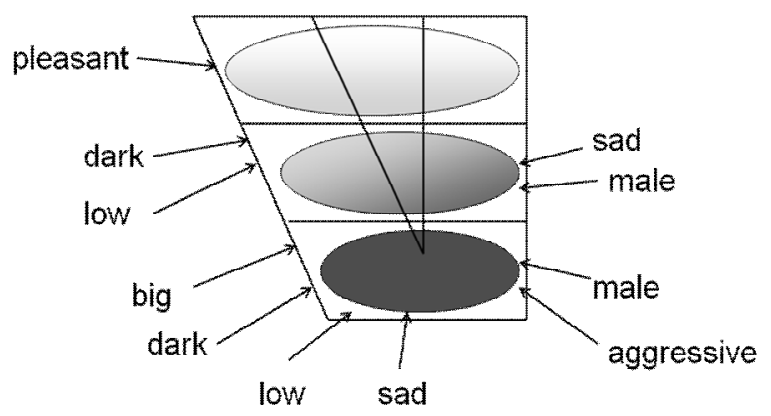

Fig. 2 Statistically significant synaesthetic mappings for high/mid/low English vowels

\subsection{Discussion}

In the present section the findings are first interpreted and then compared against other studies on sound symbolism and synaesthesia as well as a series of experiments on sound-colour coding conducted by the present author (Wrembel 2007, Wrembel \& Rataj 2008, Wrembel 2009).

As it appears from the analysis of the presented research results, it is more the qualitative differences (i.e. the length of the vowel) that determine its symbolic size perception as belonging to the 'big' vs. 'small' category, rather than the vowel high or low frequency as specified in the Frequency Code hypothesis (Ohala 1984, 2006). Consequently, the present findings show that the vowel duration and the accompanying degree of muscular tension act as determinants of the perceived salience.

On the other hand, the results of the location variable analysis correspond to a large extent to Ohala's (2006) Frequency Code predictions and to previous research findings, with physically high objects being associated with /i:/ and low objects with /a:/ /o:/ / $/$ 
$/ \Lambda / / 3: /$. On the whole, the present findings indicate that vowels with high F2 tend to be perceived as 'high' and those with low F2 are assigned to the 'low' category.

As far as the emotional loading is concerned, the selected variables included 'pleasant' vs. 'unpleasant' and 'happy' vs. 'sad' distinctions. In the former case, the pattern of symbolic associations with 'pleasantness' was varied and included the most peripheral vowels such as /i:/ /e/ /a:/ /o:/ / / / u:/ whereas the only vowel perceived as 'unpleasant' was the central vowel /3:/. It corresponds to the symbolic association assigned to this sound in some pronunciation pedagogy literature as it tends to be referred to as "the sound of disgust" (cf. Kelly 2000). It appears from the 'happy' vs. 'sad' vowel assignment that generally vowels with high F2 tend to symbolise 'happiness', whereas those with low F2 are related to 'sadness'. The 'happy' vs. 'sad' vowel mappings generated comparable results to the 'bright' vs. 'dark' distinction with the front vowels associated with 'happy' and 'bright' categories' and the back/central and low vowels assigned symbolically to 'sadness' and 'darkness'.

No regular tendencies were observed for the vowel-to-texture mappings involving the 'soft' vs. 'hard' distinction.

The present assignment of vowels to the luminescent category corroborates previous research findings on synaesthesia that demonstrated a tendency among both synaesthates and non-synaesthetes to associate high pitch prominent sounds with lighter colours and low pitch tones with darker colours (cf. e.g. Simner et al. 2005, Ward et al. 2006). This led to the conclusion that pitch-lightness associations reported in synaesthesia tend to be non-random also in a normal non-synaesthetic population, as it supported Ward et al.'s hypothesis (2006) that synaesthetes and non-synaesthetes apply the same cognitive mechanisms to perform sound-to-luminescence mapping. Furthermore, the findings offer some support for the cross-modal nature of normal perception. However, the soundcolour associations generated by the general public cannot be expected to equal the consistency demonstrated by synaesthetes, as shown also by Ward et al. (2006) and Simner et al. (2005).

The results of the present study are also very much in line with a series of experiments on multimodal sound-colour correspondence in L1 and L2 in a nonsynaesthetic population (Wrembel 2007, 2009; Wrembel \& Rataj 2008). The vowelcolour interactions generated in these studies demonstrated non-arbitrary patterns of distribution, in which specific phonemic features triggered particular colour attributes, namely front vowels were associated with bright colours; back vowels with darker hues; open vowels generally with red; and central vowels with achromatic grey. The analysis relied mostly on local characteristics of formant frequencies as perceptual parameters used to categorised vowel colour. Sounds with more high-frequency energy as /i:/ tended to generate in the experiments bright colour associations (yellow, green) as opposed to lower-frequency sounds, e.g. /u:/ that triggered darker colours (brown, blue and black). The results of these studies may serve as an experimental validation of most of the predictions for vowel colours put forward by Jakobson (1962) and Donegan (1985).

All in all, the present findings point to regular tendencies in associating particular sensations (e.g. size, luminescence, location, texture or emotional loading) with specific 
acoustic quality of phonemic segments thus providing some further support for previous studies on sound symbolism (e.g. Hinton et al. 2006).

However, the study differs from the majority of previous experiments on acoustic iconicity since it was conducted on a population of advanced EFL learners of English and one of the expectations was to generate some potential implications for foreign language pronunciation pedagogy.

\section{Pedagogical implications of sound symbolism}

The results of this study point to the possibility of iconic representations that may accompany and reinforce conscious perceptual experience of speech sounds and thus be applicable to the process of foreign language teaching to facilitate the acquisition of the target language sounds.

If a form of vocalisation is linked to meaning as is the case in sound symbolism, the potential for accurate and fast comprehension and stimulus detection is enhanced. Therefore, through assigning vivid symbolic characteristics to the target language sounds, long-term auditory memory is enhanced, L2 phonemic representations are reinforced, and additional affective learning pathways are activated, thus, the process of phonological acquisition of a foreign language may be facilitated.

As a follow-up to the study the present author conducted a preliminary overview of English pronunciation teaching resources with the aim to exploring if pronunciation textbooks apply elements of sound symbolism in the proposed classroom activities. It appears that a resource book that frequently relies on sound symbolic associations is Pronunciation by Laroy (1995). A selection of innovative exercises and classroom activities based on synaesthetic associations is presented below to illustrate this point.

One of the exercises aimed at perceptual tuning into the language is My perception of English (Laroy 1995: 24-29). With a view to fostering positive attitudes to the target language, the exercise relies entirely on sound symbolic associations as the learners are asked to explore their reactions to the sound of English by selecting some of the provided similes. For instance, when you listen to English it sounds like a drum or a violin; it reminds you of a female or a male; you feel like strolling or running; you can taste chocolate or sand; it feels like a rough wall or tissue paper.

Another example of a synaesthetic classroom activity for teaching L2 pronunciation is Sounds and senses (Laroy 1995: 86-87) which requires the learner to associate sounds with other senses, e.g. tastes, textures or colours in order to distinguish better between e.g. pairs of sounds. For this purpose contrasting sound pairs are ascribed to particular polar adjectives of sense to make them more memorable through reinforcing mental representations of L2 sounds and creating additional sensory links, be it visual, proprioceptive or tactile. It is, therefore, proposed that certain pairs of sounds like $\mathrm{s} / \mathrm{z}$, $\mathrm{f} / \mathrm{v}, \mathrm{t} \mathrm{d} / \mathrm{d} z$ are to be matched with one of the following antonymic pairs of words: savoury vs. sweet; plain vs. spicy; raw vs. cooked, crunchy vs. soft; juicy vs. dry.

Sound and movement (Laroy 1995: 89-90), in turn, constitutes a sound symbolic activity aimed at creating kinaesthetic representations of L2 sounds. Laroy puts forward a proposal to associate classes of sounds with particular movements which represent 
symbolically the inherent characteristics of these sounds. For instance, short vowels tend to be represented with short movements with a hand or finger to mirror the movement of the tongue; long vowels, on the other hand, are portrayed by larger hand or arm movement or by sitting down and standing up. Voiceless plosives $/ \mathrm{p} / / \mathrm{t} / / \mathrm{k} /$ are suggested to be mirrored by short sudden movements like clapping, whereas fricatives and affricates by larger movements like pushing outwards with hands. It is worth noting that these suggestions remain mostly in line with Swadesh's (1971) observations of natural languages in which he noted e.g. sound symbolic associations of voiceless obstruents with sharp and rapid movements; and of nasals with heavy and slow continuity.

Direct symbolic associations are also encouraged in The happiest sound activity (Laroy 1995: 92-93) in which the learners are asked to classify and label the inherent 'character' of a sounds, e.g. by agreeing on the happiest, the funniest, the lowest, the most boring, the most catlike or the most childish sound. An extension of this activity consists in drawing particular sounds rather than assigning specific linguistic labels to them (Draw the sound Laroy 1995: 93-94).

Similar activities geared at facilitating discrimination of the target speech sounds through associations with non-speech sounds (e.g. sounds of the environment) rely on sound metaphors or similes (Sound metaphors Laroy 1995: 91-92). Examples of such partially onomatopoeic metaphors include /z/ - buzz bee, /p/ - cork popping, /av/ - cat mewing.

One of the most intriguing proposals for reinforcing the acquisition of L2 phonemes based on iconicity consists in associating pieces of music with specific sound classes (Musical sounds, Laroy 1995: 95-97). The author suggests that the teaching of voiceless plosives and short vowels could be accompanied by pieces of music with striking rhythm element, e.g. Dvoŕák symphony or Kitaro, whereas more flowing melodic tunes e.g. Mozart Flute concerto, Paganini violin concerto seem to reflect better voiced plosives and fricatives. Long vowels and diphthongs are symbolically associated with slow tunes, e.g. Johan Strauss 'Blue Danube' waltz, Gregorian chants, or The Beatles 'Yesterday'.

Examples of phonesthetic associations used in the pronunciation classroom can be found also in Kelly (2000) How to teach pronunciation. With the view to raising awareness of vowel sounds the author evokes several sound symbolic associations, e.g. /i:/ - a smiling sound, /ui/ - surprising gossip,/a/ - Friday afternoon sound, /3:/ 'something horrible' sound, /a:/ 'holding the baby' sound (Kelly 200: 37-39).

This sound symbolic approach manifests itself in the use of multisensory modes of presentation and practice. The process of teaching and learning L2 pronunciation is thus expected to be enhanced by appealing to a combination of modalities involving different senses through auditory, visual, tactile, kinaesthetic reinforcements.

\section{Conclusions}

The present investigation was limited to one type of acoustic iconicity in which the sounds were assigned visual, tactile or emotional characteristics. The synaesthetic associations with English vowels generated in the study demonstrated fairly nonarbitrary patterns of distribution, similar to those widely discussed in the literature, in which specific phonemic features trigger particular sensory attributes of size, 
luminescence, texture and location as well as emotionally-loaded connotations. Further systematic research into the phenomenon of sound synaesthetic mappings is needed to verify the hypothesis of language form-to-meaning correspondence more thoroughly. Moreover, it is hoped that the discussed sound symbolic classroom activities may raise awareness of the existing potential of cross-modal mechanisms that may be applied to facilitate foreign language learning.

\section{References}

Berlin, B. 2006. Evidence for pervasive synesthetic sound symbolism in ethnozoological nomenclature. In Hinton, L., J. Nichols and J. Ohala (eds.), Sound Symbolism. Cambridge: Cambridge University Press, 76-93.

de Saussure, F. 1966. Course in general linguistics. New York: McGraw-Hill.

Donegan, P. 1985. On the Natural Phonology of Vowels. New York: Garland Publishing.

Diffloth, G. 2006. i: big, a: small. In Hinton, L., J. Nichols and J. Ohala (eds.), Sound Symbolism. Cambridge: Cambridge University Press, 107-114.

Hinton, L., J. Nichols and J. Ohala. 2006. Introduction: Sound-symbolic processes. In Hinton, L., J. Nichols and J. Ohala (eds.), Sound Symbolism. Cambridge: Cambridge University Press, 1-14.

Hinton, L., J. Nichols and J. Ohala (eds.). 2006. Sound Symbolism. Cambridge: Cambridge University Press.

Jakobson, R. 1962. Selected Writings: I Phonological Studies .The Hague: Mouton.

Jespersen, O. 1933. Symbolic value of the vowel i. Linguistica. Selected Papers in English, French and German. Copenhagen: Levin \& Munksgaard, 283-303.

Kelly, G. 2000. How to teach pronunciation. Harlow: Longman.

Lapolla, R. 2006. An experimental investigation into phonetic symbolism as it relates to Mandarin Chinese. In Hinton, L., J. Nichols and J. Ohala (eds.), Sound Symbolism. Cambridge: Cambridge University Press, 130-147.

Laroy, C. 1995. Pronunciation. Oxford: Oxford University Press.

Ohala, J. 1984. An ethological perspective on common cross-language utilization of F0 in voice. Phonetica 41: 1-16.

Ohala, J. 2006. The frequency code underlies the sound-symbolic use of voice pitch. In L. Hinton, J. Nichols and J. Ohala (eds.), Sound Symbolism. Cambridge: Cambridge University Press, 325-347.

Oswalt, R. 2006. Inanimate imitatives in English. In Hinton, L., J. Nichols and J. Ohala (eds.), Sound Symbolism. Cambridge: Cambridge University Press, 293-305.

Rhodes, R. 2006. Aural images. In Hinton, L., J. Nichols and J. Ohala (eds.), Sound Symbolism. Cambridge: Cambridge University Press, 276-291.

Sapir, E. 1927. Language as a form of human behaviour. The English Journal 16: 215234.

Sapir, E. 1929. A study of phonetic symbolism. Journal of Experimental Psychology 12: 225-239.

Sereno, J. 2006. Phonosyntactics. In Hinton, L., J. Nichols and J. Ohala (eds.), Sound Symbolism. Cambridge: Cambridge University Press, 263-275. 
Simner, J., J. Ward, A. Jansari, K. Noonan and D. Oakley. 2005. Non-random associations of graphemes to colours in synaesthetic and non-synaesthetic populations. Cognitive Neuropsychology 22, 1-17.

Swadesh, M. 1971. The origin and diversification of language. Chicago: Aldine and Co.

Ultan, R. 1978. Size-sound symbolism. In Greenberg, J. (ed.), Universals of human language, volume 2: Phonology. Stanford: University Press.

Ward, J., B. Huckstep and E. Tsakanikos. 2006. Sound-colour synaesthesia: to what extent does it use cross-modal mechanisms common to us all? Cortex, 42, 264-280.

Wrembel, M. 2007. Still sounds like a rainbow - a proposal for a coloured vowel chart. Proceedings of the Phonetics Teaching and Learning Conference PTLC2007 (CD edition). London: UCL, 1-4.

Wrembel, M. 2009. On hearing colours - cross-modal associations in vowel perception in a non- synaesthetic population. Poznań Studies in Contemporary Linguistics 45(4), 595-612.

Wrembel, M. and K. Rataj. 2008. Sounds like a rainbow - sound-colour mappings in non-synaesthetic population. In Botinis, A. (ed.), Proceedings of the 2nd ISCA Workshop on Experimental Linguistics, ExLing 2008, Athens: University of Athens, 237-240. 


\section{Appendix}

\section{Sound 1 /iis/}

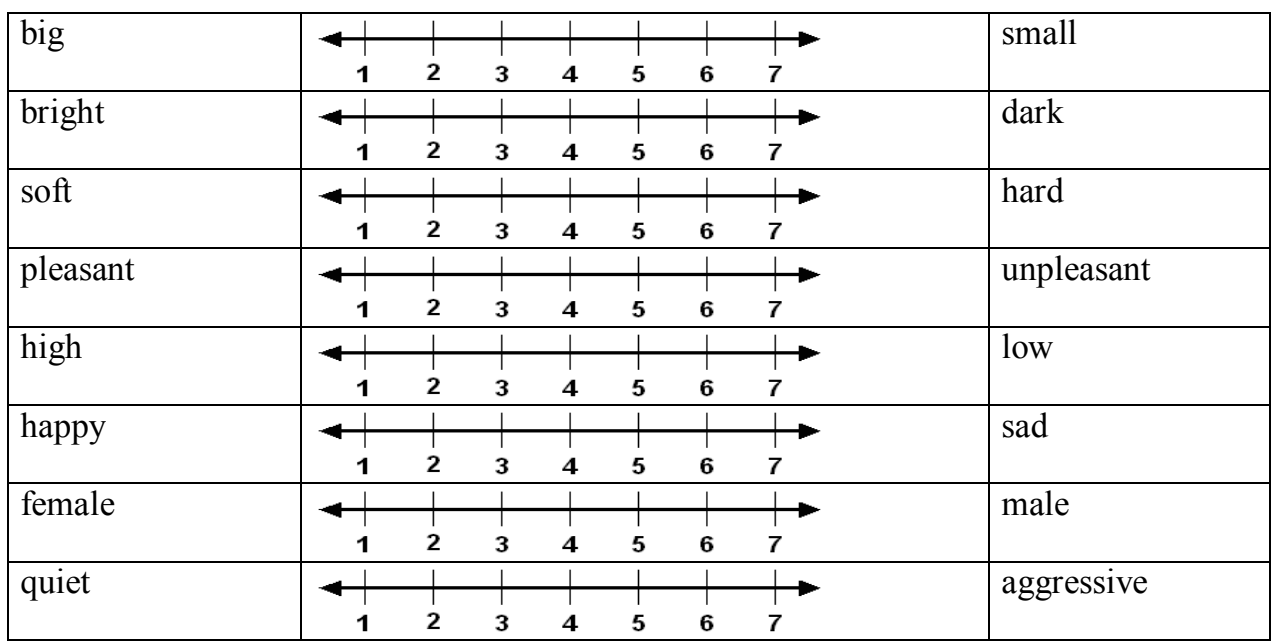

